\title{
Narrative review of management strategies and outcomes in node-positive prostate cancer
}

\author{
Kevin A. D'Rummo, Ronald C. Chen, Xinglei Shen^ \\ Department of Radiation Oncology, The University of Kansas Medical Center, Kansas City, KS, USA \\ Contributions: (I) Conception and design: All authors; (II) Administrative support: All authors; (III) Provision of study materials or patients: All \\ authors; (IV) Collection and assembly of data: All authors; (V) Data analysis and interpretation: All authors; (VI) Manuscript writing: All authors; (VII) \\ Final approval of manuscript: All authors. \\ Correspondence to: Xinglei Shen, MD. Department of Radiation Oncology, The University of Kansas Medical Center, 4001 Rainbow Blvd., Mailstop \\ 4033, Kansas City, KS 66160, USA. Email: xshen@kumc.edu.
}

\begin{abstract}
Pelvic nodal involvement is present in $13 \%$ of new prostate cancer diagnoses each year and is associated with a poor prognosis compared to localized disease. Grouped as stage IV along with distant metastatic disease, node-positive nonmetastatic patients historically received systemic therapy alone as primary treatment. This treatment paradigm has shifted as data have demonstrated that these patients may benefit from aggressive locoregional therapy and are potentially curable. There is currently a lack of randomized evidence to define the optimal management for node-positive patients. While a few trials have included node-positive patients, the majority of data are derived from large multi-institutional series or population-based series. This narrative review summarizes the current literature supporting curativeintent management strategies for patients diagnosed with nonmetastatic clinically node-positive prostate cancer (cN1M0), as well as patients found to have pathologic nodal disease at the time of surgery (pN1M0). Treatment of both scenarios requires multimodality considerations including surgery, radiation therapy (RT) and systemic therapy to minimize the risks of both locoregional and distant recurrence. Future considerations include developments in enhanced imaging and systemic therapy. Inclusion of node-positive patients on prospective, randomized trials such as NRG GU 008 is needed to enhance our understanding of optimal management strategies.
\end{abstract}

Keywords: Lymph node metastasis; prostate cancer; radiation; prostatectomy

Submitted Jun 23, 2020. Accepted for publication Oct 27, 2020.

doi: $10.21037 /$ tau-20-1031

View this article at: http://dx.doi.org/10.21037/tau-20-1031

\section{Introduction}

Approximately $13 \%$ of the 191,930 patients newly diagnosed with prostate cancer in the United States in 2020 will present with metastasis to the regional lymph nodes (N1M0) (1). In the current American Joint Committee on Cancer (AJCC) $8^{\text {th }}$ edition staging manual, metastasis to pelvic lymph nodes (pelvic, hypogastric, obturator, iliac, sacral) are classified as N1, and are group stage IV-A (2).
Historically, clinicians have grouped prostate cancer that have metastasized to lymph nodes together with distant metastasis in the same category of advanced prostate cancer. However, evolving data now support the management of N1M0 patients akin to locally advanced prostate cancer, including the use of multimodality therapy to reduce recurrence, improve survival, and potentially cure a portion of patients. Due to a paucity of randomized evidence in this area, the management of this patient population varies

^ ORCID: 0000-0003-0337-860X. 
Table 1 Studies evaluating ADT and systemic treatments for node-positive prostate cancer

\begin{tabular}{|c|c|c|c|c|c|}
\hline Study & Study design & $\mathrm{N}$ & Treatment & $\begin{array}{l}\text { Median } \\
\text { follow-up (yr) }\end{array}$ & Study outcomes \\
\hline EORTC 30846 (3) & $\begin{array}{l}\text { Randomized } \\
\text { trial }\end{array}$ & 234 & $\begin{array}{l}\text { Immediate vs. } \\
\text { delayed ADT }\end{array}$ & 13.0 & $\begin{array}{l}\text { Median OS } 6.1 \text { yr (delayed) vs. } 7.6 \text { yr; NS } \\
\text { 10-yr CSS } 44.4 \% \text { (delayed) vs. } 47.9 \% \text {; NS }\end{array}$ \\
\hline $\begin{array}{l}\text { STAMPEDE } \\
\text { James et al. } \\
2017 \text { (4) }\end{array}$ & $\begin{array}{l}\text { Randomized } \\
\text { trial }\end{array}$ & $\begin{array}{l}1,917(\mathrm{~N} 1 \mathrm{M0} \\
\mathrm{n}=369)\end{array}$ & $\begin{array}{l}\mathrm{ADT} \pm \text { abiraterone/ } \\
\text { prednisolone }\end{array}$ & 3.3 & $\begin{array}{l}\text { Favors ADT + abiraterone } \\
\text { 3-yr OS } 76 \% \text { vs. } 83 \% \text {; } P<0.001 \\
\text { 3-yr FFS } 45 \% \text { vs. } 75 \% \text {; } P<0.001\end{array}$ \\
\hline GETUG-12 $2^{\ddagger}(5)$ & $\begin{array}{l}\text { Randomized } \\
\text { trial }\end{array}$ & $\begin{array}{l}413(\mathrm{~N} 1 \mathrm{MO} \\
\mathrm{n}=119)\end{array}$ & $\begin{array}{l}\text { ADT } \pm \text { docetaxel } \\
\text { and estramustine }\end{array}$ & 8.8 & $\begin{array}{l}\text { Favors ADT + docetaxel/estramustine } \\
\text { 8-yr RFS } 50 \% \text { vs. } 62 \% \text {; } P=0.017\end{array}$ \\
\hline $\begin{array}{l}\text { STAMPEDE } \\
\text { James et al. } \\
2016(6)\end{array}$ & $\begin{array}{l}\text { Randomized } \\
\text { trial }\end{array}$ & $\begin{array}{l}2,962(\mathrm{~N} 1 \mathrm{M} 0 \\
15 \%)\end{array}$ & $\begin{array}{l}\mathrm{ADT} \pm \text { docetaxel } \pm \\
\text { zoledronic acid }\end{array}$ & 3.6 & $\begin{array}{l}\text { Favors ADT + docetaxel } \\
\text { Median OS } 40 \text { mo (ADT alone) vs. } 60 \mathrm{mo} ; \mathrm{P}=0.005 \\
\text { Mean FFS } 35 \text { mo (ADT alone) vs. } 44 \mathrm{mo} ; \mathrm{P}<0.001\end{array}$ \\
\hline
\end{tabular}

${ }^{\dagger}$, Study included M1, N1M0, and N0M0 patients with two or more high-risk features (T3-4, Gleason score $\geq 8, \mathrm{PSA} \geq 40 \mathrm{ng} / \mathrm{mL}$ ). ${ }^{\ddagger}$, Study included N1M0 and NOM0 patients with one or more high-risk feature (T3-4, Gleason score $\geq 8$, PSA $\geq 20$ ng/mL). ADT, androgen deprivation therapy; EORTC, European Organization for Research and Treatment of Cancer; OS, overall survival; CSS, cancer-specific survival; NS, not significant; FFS, failure-free survival; N/A, not available; ng/mL, nanogram per milliliter; RFS, relapse-free survival; PSA, prostate-specific antigen.

widely in clinical practice. This article reviews the relevant studies that have shaped the modern management of nodepositive prostate cancer patients and summarizes their associated outcomes. We present the following article in accordance with the Narrative Review reporting checklist (available at http://dx.doi.org/10.21037/tau-20-1031).

\section{Management of clinically node-positive, nonmetastatic (cN1M0) prostate cancer}

\section{Androgen deprivation therapy (ADT) without local therapy}

ADT historically was an accepted treatment for patient with cN1M0 prostate cancer. This follows the paradigm for patients with metastatic prostate cancer (M1) where ADT is the long-established standard of care. ADT in node-positive patients is generally initiated at the time of diagnosis rather than delayed. The randomized EORTC 30846 trial evaluated the non-inferiority of delayed ADT compared to immediate ADT in 234 patients diagnosed with nodal disease by biopsy or staging lymphadenectomy (Table 1) (3).

No local treatment was offered to the primary tumor. The intent-to-treat analysis showed a $22 \%$ [hazard ratio (HR): $1.22 ; 95 \%$ CI: $0.92-1.62]$ increase in the hazard of death with delayed ADT, though this did not reach statistical significance. Median overall survival (OS; 7.6 vs. 6.1 years) and 10-year cancer-specific survival (CSS; $47.9 \%$ vs. $44.4 \%$ ) were not statistically significantly different between the immediate and delayed ADT arms. This trial was unable to demonstrate non-inferiority of delayed ADT, thus starting $\mathrm{ADT}$ at the time of diagnosis remains the standard of care.

Intermittent ADT has not specifically been studied in cN1M0 patients, so its use is not recommended. The SWOG 9346 trial randomized newly diagnosed M1 patients to continuous versus intermittent $\operatorname{ADT}(7)$, and was unable to conclude non-inferiority of intermittent ADT by excluding $20 \%$ increased risk of death with intermittent ADT. However, the applicability of results from this trial to patients with $\mathrm{cN} 1 \mathrm{M} 0$ disease is unclear.

For M1 patients, several large randomized trials demonstrated improvement in OS with the addition of advanced hormonal therapy (e.g., abiraterone, enzalutamide, apalutamide) to ADT in hormone sensitive metastatic prostate cancer (8-10). However, none of these trials specifically studied cN1M0 patients. The STAMPEDE trial investigated the addition of abiraterone to ADT in a heterogenous population of men with M1 (53\%), N1M0 (20\%), or localized high risk prostate cancer (27\%) (4). Local therapy with radiotherapy was optional for N1M0 patients. Abiraterone improved failure-free 
survival (FFS) in the overall study population (HR: 0.29; $\mathrm{P}<0.001)$ with similar effect on the N1 (HR: 0.29) and M0 (HR: 0.21) patient subsets. However, N1M0 patients were not specifically analyzed. Abiraterone was also associated with improved OS for the overall study population (HR: 0.63; 95\% CI: $0.5-0.76 ; \mathrm{P}<0.001)$ and on subset analysis for patients with any nodal dissemination (HR: 0.61; $95 \%$ CI: 0.48-0.77). Again, data for N1M0 patients were not separately analyzed. This study suggests but does not clearly demonstrate that the addition of abiraterone to standard ADT improves cancer control or survival outcomes in N1M0 patients.

\section{$A D T+$ radiation therapy $(R T)$}

Definitive RT for cN1M0 prostate cancer most commonly covers the pelvic nodal regions, prostate and seminal vesicles. In randomized clinical trials, adding RT to ADT has demonstrated an improvement in survival in patients with high-risk localized disease (less advanced than N1M0 disease) and also in hormone sensitive M1 disease (more advanced than N1M0). Two large randomized trials compared indefinite $\mathrm{ADT}$ alone $v s$. $\mathrm{ADT}+\mathrm{RT}$ in patients with high risk localized prostate cancer. The SPCG-7 reported a dramatic reduction in prostate-specific antigen (PSA) recurrence (HR: 0.16; 95\% CI: 0.12-0.20; P<0.0001) and improved prostate CSS (HR: 0.44; 95\% CI: 0.30-0.66; $\mathrm{P}<0.001)$ (11) from the addition of RT. NCIC PR.3 reported similar improvement in prostate CSS (HR: 0.46; $95 \%$ CI: 0.34-0.66; $\mathrm{P}<0.001)(12)$. In hormone sensitive M1 prostate cancer, the $\mathrm{H}$-arm of the STAMPEDE trial compared ADT + prostate RT to ADT alone (13). In a pre-specified subset analysis of patients with low metastatic burden, the addition of prostate RT improved both FFS (HR: 0.59; 95\% CI: 0.49-0.72; $\mathrm{P}<0.001$ ) and OS (HR: 0.65; 95\% CI: 0.47-0.90; $\mathrm{P}=0.01$ ). Of note, node-positive prostate cancer is a disease state between localized and metastatic prostate cancers. Extrapolation of improved survival from these randomized trials in patients with less advanced (high risk localized) and more advanced (low volume M1) prostate cancer provides a rationale for the potential benefit of adding RT to ADT for $\mathrm{N} 1 \mathrm{M} 0$ positive cancer.

Retrospective series also provide evidence for the role of RT in cN1M0 prostate cancer. With caveats of potential uncontrolled confounders and selection bias, these studies have consistently demonstrated improvements in both cancer control and survival outcomes (Table 2). One prospective randomized trial, RTOG 9608, attempted to compare $\mathrm{RT}$ and $\mathrm{ADT}$ versus $\mathrm{ADT}$ alone in node-positive patients but it was terminated early due to poor accrual.

The largest single institution series from the MD Anderson Cancer Center retrospectively evaluated 255 men with pelvic nodal metastases identified on staging pelvic lymphadenectomy treated with either ADT alone or ADT + RT (14). ADT consisted of orchiectomy or medical castration. External beam radiotherapy (EBRT) was delivered to the prostate in 72 patients, with doses ranging from 60-78 (median 68) Gy. After a median follow-up of 6.2 (ADT + RT) to 9.4 (ADT alone) years, patients who received $\mathrm{ADT}+\mathrm{RT}$ demonstrated superior 10-year OS (46\% vs. 67\%; $\mathrm{P}=0.008)$, local control (LC) (49\% vs. $89 \%$; $\mathrm{P}<0.001)$, freedom from biochemical relapse ( $25 \%$ vs. $80 \%$; $\mathrm{P}<0.001)$, and freedom from distant metastasis $(\mathrm{FFDM})$ ( $56 \%$ vs. $85 \% ; \mathrm{P}=0.006$ ).

An unplanned analysis of N1M0 patients from the control arm of the STAMPEDE trial also support the addition of RT (18). All patients received ADT on the control arm of the trial, and RT was optional for N1M0 patients. Of the 157 patients included in the analysis, $45 \%$ $(\mathrm{n}=71)$ received RT to doses at discretion of the treating physician. The addition of RT to ADT was associated with higher 2-year FFS (89\% vs. 64\%; HR: 0.35; 95\% CI: 0.19-0.65) after adjusting for Gleason score, PSA, age and performance status. OS data have not yet been presented.

Population and hospital-based studies have also reported improvement in OS with the use of RT in patients with N1M0 prostate cancer. Tward et al. used the Surveillance Epidemiology \& End Results (SEER) database to compare outcomes in node-positive patients diagnosed from 1988-2006 who received RT versus no local therapy. On multivariable analysis, RT was associated with an improvement in CSS (HR: 0.67; 95\% CI: 0.54-0.84; $\mathrm{P}<0.01$ ); 10 -year CSS results were $50.3 \%$ vs. $62.7 \%$ (15). Similar results were noted by Rusthoven $e t$ al. in a separate SEER study of local therapy for node-positive cancer (16). Of note, the use of ADT was not recorded in the SEER and is a major limitation to these analyses. An analysis of the National Cancer Database (NCDB) compared OS in a propensity matched cohort of 636 node-positive patients receiving $\mathrm{ADT}$ alone $(\mathrm{n}=318)$ or $\mathrm{ADT}+\mathrm{RT}(\mathrm{n}=318)(17)$. Of those receiving $\mathrm{RT}$, $97 \%$ received $\mathrm{RT}$ with median doses of 50.4 Gy to the pelvis and 75.6 Gy total. The use of combined ADT + RT was associated with an approximately $50 \%$ reduction in all-cause mortality at 5 years compared to ADT alone (HR: 0.50; 95\% CI: 0.37-0.67; $\mathrm{P}<0.001$ ).

Overall, the published evidence including clinical trials 
Table 2 Studies evaluating definitive radiotherapy for node-positive prostate cancer

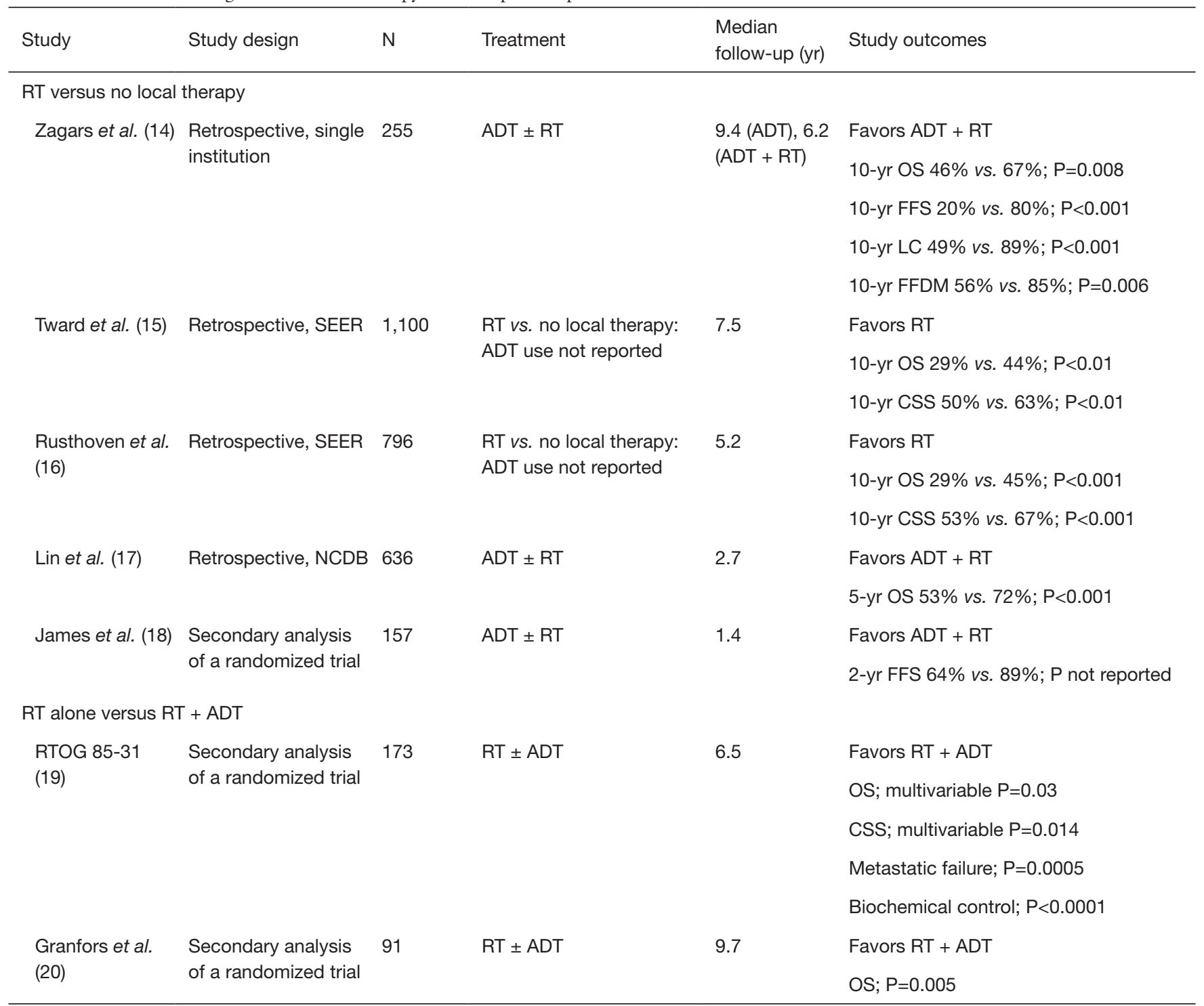

ADT, androgen deprivation therapy; RT, radiotherapy; CSS, cancer-specific survival; OS, overall survival; LC, local control; FFDM, freedom from distant metastasis; FFS, failure-free survival; Gy, Gray; SEER, Surveillance Epidemiology \& End Results; NCDB, National Cancer Database.

and retrospective studies support the addition of prostate $\mathrm{RT}$ to ADT for the treatment of cN1M0 patients.

\section{$A D T+$ radical prostatectomy $(R P)$ with extended pelvic lymph node dissection (ePLND)}

The evidence for definitive surgery for patients with known nodal disease is limited. RP with or without PLND is one standard of care in patients with localized prostate cancer. However, for clinically node-positive disease, the use of RP remains controversial. The EAU-ESTRO-SIOG allows for RP with ePLND in very selected patients, whereas this is not a recommendation in the NCCN guidelines (Table 3).

Historically, planned prostatectomies have been abandoned for futility upon finding of lymph node metastasis during the lymph node dissection (24). This perspective has been challenged with multiple retrospective series which have reported improvement in survival with RP in node-positive prostate cancer (see section "Management for pathologically node-positive prostate cancer"). It is 
Table 3 Current guidelines on the management of N1M0 prostate cancer

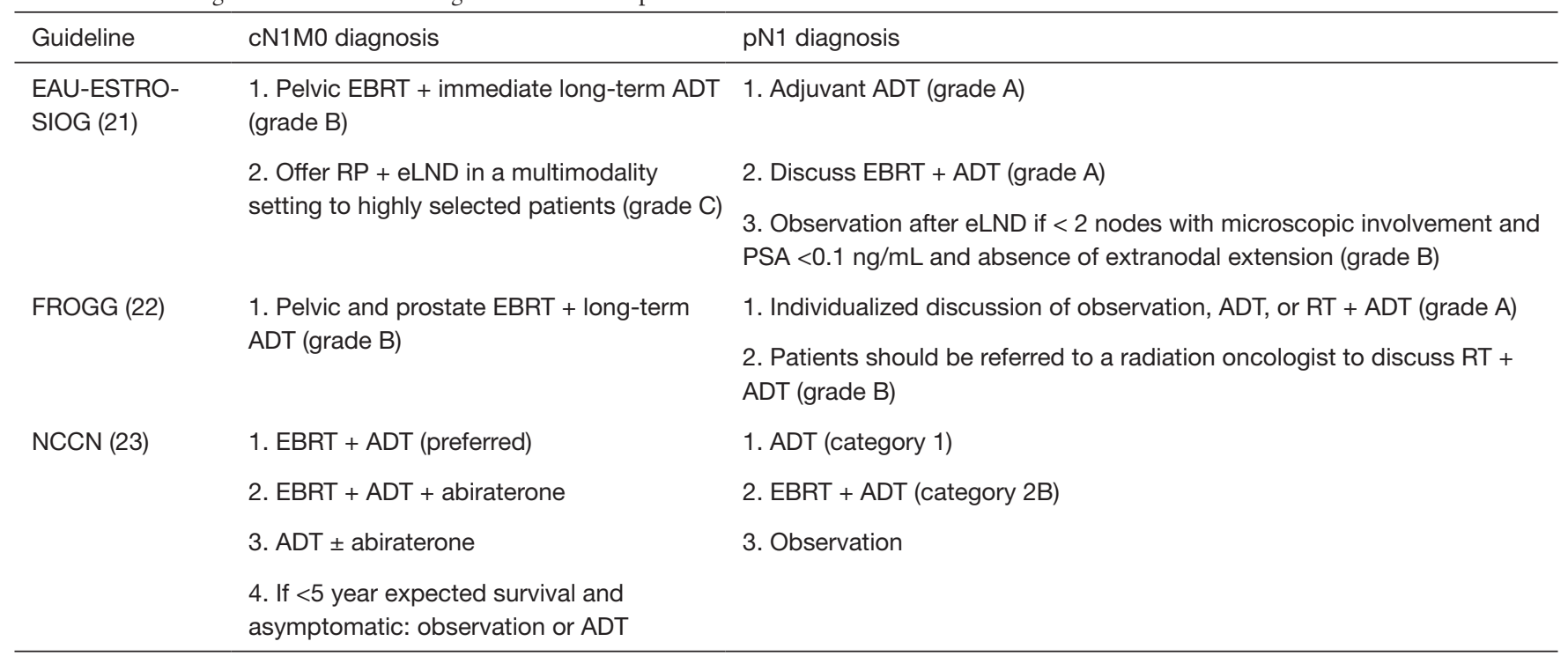

EBRT, external beam radiotherapy; ADT, androgen deprivation therapy; RP, radical prostatectomy; eLND, extended lymph node dissection; PSA, prostate-specific antigen; EUA, European Association of Urology; ESTRO, European Society for Radiotherapy and Oncology; SIOP, International Society of Pediatric Oncology; FROGG, Faculty of Radiation Oncology Genitourinary Group (Australia); NCCN, National Comprehensive Cancer Network.

important to note a distinction between clinical nodepositive $(\mathrm{cN}+)$ and pathologic node-positive $(\mathrm{pN}+)$ prostate cancer. Many of the patients with pathologically detected lymph node metastasis after PLND had clinically negative nodes (cN0) pre-operatively.

Data on the role of prostatectomy in $\mathrm{cN}+$ patients are limited. Seisen et al. used the NCDB to compare outcomes in $\mathrm{cN} 1 \mathrm{M} 0$ patients treated with $\mathrm{ADT}$ versus $\mathrm{RP}+\mathrm{ADT}$, and reported an improvement in 5 -year OS from $49.2 \%$ to $78.8 \%$ (HR: 0.31 ; 95\% CI: 0.13-0.74; $\mathrm{P}=0.007$ ) (25). This study also compared outcomes of ADT + RT, and found ADT + either RP or RT had similar improvements compared to ADT alone. These data suggest that local therapy, regardless of modality, may confer a survival improvement compared to ADT alone.

\section{$R T \pm A D T$}

Randomized data suggest that local therapy alone is not sufficient for patients with node-positive cancer. Multiple randomized studies have demonstrated improvements in OS, biochemical control, and distant failure when ADT is added to RT for localized and locally advanced prostate cancers $(19,20,26-28)$. Two smaller trials specifically provide data related to RT vs. RT + ADT in node-positive disease
(Table 2). The RTOG 8531 trial randomized 977 patients with either nodal metastasis or clinical T3 prostate cancer to RT + ADT versus RT alone. Post-prostatectomy patients were allowed if they contained pT3 disease or involved margins. A subgroup analysis of patients with node-positive prostate cancer $(\mathrm{n}=173)$ showed that combination RT + ADT was associated with improved absolute survival $(\mathrm{P}=0.03)$, cause-specific failure $(\mathrm{P}=0.014)$, metastatic failure $(\mathrm{P}=0.0005)$, and biochemical control $(\mathrm{P}<0.0001)$ compared to RT alone (19). A Swedish trial randomized node-positive patients to RT or RT plus orchiectomy (20). Initially planned for 400 patients, the study closed early after 91 patients when interim analysis showed significant rates of disease progression in the RT alone arm. Combined modality therapy showed a significant OS benefit $(\mathrm{P}=0.005)$ at a median follow-up of 9.7 years. These data established the need to add ADT to RT for this patient population.

The optimal duration of ADT with definitive RT in the cN1M0 setting is not established. Clinicians have commonly extrapolated from trials of locally advanced prostate cancer to offer 2-3 years of ADT $(29,30)$.

\section{Chemotherapy}

The role of chemotherapy in the primary management of 
node-positive prostate cancer is controversial. The addition of chemotherapy improves survival in patients with castratesensitive M1 prostate cancer, a disease state that is more advanced than N1M0 prostate cancer, though this benefit may be limited to patients with high volume disease (31). Data for chemotherapy in patients with N1M0 cancer are limited. Patients with node-positive cancer have been included in two randomized trials evaluating the addition of chemotherapy (Table 1). GETUG AFU-12 randomized 413 patients with N1M0 (29\%) or high-risk N0M0 prostate cancer $(71 \%)$ to receive either 3 years of ADT plus four cycles of docetaxel and estramustine, or ADT alone (5). Almost all patients also received local therapy. The primary endpoint of relapse-free survival (RFS) at 8 years was improved with ADT plus chemotherapy compared to ADT alone (62\% vs. $50 \%$; adjusted HR: 0.71; 95\% CI: 0.54-0.94; $\mathrm{P}=0.017)$. OS at 8 years was $83 \%$ for both arms combined; however, there were too few events to analyze the N1M0 and N0M0 groups separately. No subgroup analysis was reported for patients with N1M0 disease.

The STAMPEDE trial randomized 2,962 prostate cancer patients to ADT alone, ADT plus six cycles of docetaxel, ADT plus zoledronic acid, or ADT plus docetaxel and zoledronic acid (6). Eligible patients were diagnosed with either M1 (61\%), N1M0 (15\%), or localized prostate cancer with at least two high-risk features (24\%). Radiotherapy was optional for N1M0 patients. OS (median 60 vs. 45 months; HR: 0.78; 95\% CI: 0.66-0.93; $\mathrm{P}=0.005$ ) and FFS (median 44 vs. 35 months; $95 \% \mathrm{CI}$ : $0.53-0.70 ; \mathrm{P}<0.001)$ were improved with the addition of docetaxel to ADT. On subset analyses of patients with M0 disease, docetaxel was associated with an improvement in FFS but not OS. A subset analysis of N1M0 only patients was not performed.

Based on these results, there is currently no clear role for chemotherapy for N1M0 prostate cancer.

\section{Management for pathologically node-positive prostate cancer}

\section{$R P$ and lymph node dissection}

Retrospective surgical series with long-term follow-up suggest a beneficial impact of RP compared to no local therapy on both overall and CSS for patients with nodepositive prostate cancer $(24,32,33)$. One large German cohort compared outcomes of patients with intraoperative finding of lymph node metastasis where the prostatectomy was abandoned versus completed (24). Completion prostatectomy was associated with an improvement in 5 -year OS from $60 \%$ to $84 \%$ (HR: 2.04; $95 \%$ CI: 1.59 2.63; $\mathrm{P}<0.0001)$. In multiple series, the reported 10 -year outcomes of $\mathrm{pN}+$ patients after RP and PLND without further adjuvant local therapy are approximately $60-66 \%$ OS and $70-85 \%$ CSS; however, only a third of patients remained free of biochemical progression (24,32-37).

In highly selected $\mathrm{pN}+$ patients with favorable disease characteristics, outcomes after surgery alone may be more favorable. A series from Mayo Clinic reported 10-year CSS as high as $94 \%$ for patients with only one positive lymph node (35). Another series reported that patients with fewer than three positive nodes and Gleason grade group 1-3 had less than a $10 \%$ risk of clinical recurrence at 8 years (38). However, it should be noted a majority of patients included in these studies received adjuvant therapies in addition to surgery. A series from Memorial Sloan Kettering Cancer Center reported 5- and 10-year freedom from biochemical recurrence of $35 \%$ and $28 \%$ following prostatectomy alone without adjuvant therapy (37). Gleason score of 8-10, multiple positive nodes, positive surgical margins, and a low total number of lymph nodes removed have been identified as predictors of higher post-prostatectomy recurrence and cancer-specific mortality (CSM) for patients with $\mathrm{pN}+$ disease $(36,37,39,40)$.

While selected $\mathrm{pN}+$ patients with favorable disease can achieve long term biochemical control with surgery alone, the addition of adjuvant therapy with ADT or ADT + RT can improve survival and is generally recommended. The following sections will review the data for these approaches.

\section{Adjuvant ADT}

The role of adjuvant ADT after RP and PLND for nodepositive patients was established by the ECOG 3886 trial (41). Messing et al. randomized 98 patients found to have pathologic node-positive cancer after RP to immediate continuous ADT $(n=47)$ or deferred $\operatorname{ADT}(n=51)$ until the development of metastasis or symptomatic recurrence. Immediate $\mathrm{ADT}$ was initiated within 12 weeks of surgery. Compared to delayed ADT, immediate adjuvant ADT was associated with superior OS (median OS 11.3 vs. 13.9 years; $\mathrm{P}=0.04$ ) and CSS (median CSS 12.3 years vs. not reached for immediate ADT; $\mathrm{P}=0.0004$ ) after 11.9 years of median follow-up. Despite its small sample size, ECOG 3886 provides the only level 1 evidence to date to guide adjuvant treatment for $\mathrm{pN}+$ disease. 
Retrospective data have been mixed. Results from a SEER-Medicare analysis of 731 men did not show a survival improvement with adjuvant ADT within 120 days of surgery compared to observation (42). After propensity score matching, there was no difference in OS (HR: 0.95; 95\% CI: 0.71-1.27) or CSM (HR: 0.97; 95\% CI: 0.56-1.68) from adjuvant ADT compared to no immediate treatment. A multi-institutional comparative analysis demonstrated improved CSM with adjuvant ADT compared to surgery alone (HR: 3.05 ; 95\% CI: $1.45-6.40 ; \mathrm{P}=0.003$ ), but OS was not improved (43). Nonetheless, based the randomized Messing data, adjuvant ADT remains a standard of care. While the ECOG 3886 trial was designed for lifelong $\mathrm{ADT}$, in actual clinical practice, stopping $\mathrm{ADT}$ at 2 years is common. The optimal duration of adjuvant ADT in $\mathrm{pN}+$ patients has not been studied prospectively.

\section{Adjuvant ADT + RT}

Many patients found to have $\mathrm{pN}+$ prostate cancer experience disease progression despite RP and adjuvant ADT $(34,39)$. Isolated locoregional recurrences after RP were observed in $31 \%$ of patients experiencing clinical progression in one series (44). No randomized trial has assessed the use of adjuvant RT for $\mathrm{pN}+$ patients. There are several retrospective studies which have demonstrated improved OS, CSS, and biochemical relapse-free survival (BCRFS) with the addition of adjuvant RT (Table 4).

A single institution series of 250 patients found that adjuvant RT was independently associated with improved CSS and BCRFS compared to adjuvant ADT alone for patients with $\mathrm{pN}+$ disease (45). A matched retrospective analysis contained $364 \mathrm{pN} 1$ patients who received either adjuvant $\mathrm{ADT}(\mathrm{n}=247)$ or adjuvant $\mathrm{RT}+\mathrm{ADT}(\mathrm{n}=171)$ after surgery (46). The addition of adjuvant RT improved both CSS (10-yr CSS: $86 \%$ vs. 70\%; $\mathrm{P}=0.004)$ and OS (10-yr OS: $74 \%$ vs. $55 \% ; \mathrm{P}<0.001)$ after matching for patient age, Gleason score, pathologic T stage, extent of nodal dissection, and follow-up length. Touijer et al. published the largest multi-institutional series to date comparing of outcomes from $1,338 \mathrm{pN}+$ patients managed with observation after RP $(n=387)$, RP plus ADT $(n=676)$, or $\mathrm{RP}$ plus ADT + RT (n=325) (43). The adjuvant ADT + RT group contained patients with higher pathologic stages and Gleason scores. Despite this, combined adjuvant ADT + RT was associated with a lower risk of all-cause mortality (HR: 0.46; 95\% CI: 0.32-0.66; $\mathrm{P}<0.0001$ ) and CSM (HR:
0.41; 95\% CI: $0.27-0.64 ; \mathrm{P}<0.0001)$ compared to adjuvant ADT. Similarly, adjuvant ADT + RT was associated with improved survival compared to observation after surgery.

Patient selection may be important when considering adjuvant radiation. Abdollah et al. compared outcomes of adjuvant ADT versus ADT + RT stratified by clinical risk factors: number of lymph nodes, Gleason score, and pathologic local extension (47). These risk features were used to stratify $\mathrm{pN}+$ patients in to five risk groups. In this analysis, only two of the five risk group subsets benefitted from the addition of RT in terms of 8-year prostate CSS: (I) patients with 3-4 positive lymph nodes; and (II) patients with 1-2 positive lymph nodes and Gleason score $\geq 7$, plus either stage pT3b-T4 or positive surgical margins. Patients with more positive nodes or lower risk disease did not demonstrate a survival benefit in this retrospective analysis. A separate study used data from the NCDB to confirm the external validity of the Abdollah et al. study, and replicated the observation that adjuvant RT only benefitted patients with 3-4 positive nodes or patients with 1-2 positive nodes plus additional adverse pathological features (52). Another analysis of the NCDB data demonstrated that the survival benefit of adjuvant RT was only apparent for patients with at least one adverse pathological feature: $\geq 3$ positive nodes, stage pT3b-4 disease, Gleason score $\geq 9$, or positive margins (51).

Overall, existing studies suggest that for patients with $\mathrm{pN}+$ disease, adding RT to adjuvant ADT likely improves long-term outcomes including survival, at least for some subgroups of $\mathrm{pN}+$ patients with certain characteristics. Accordingly, the EAU guidelines (grade A) and NCCN guidelines (category $2 \mathrm{~B}$ ) recommend adjuvant RT plus $\mathrm{ADT}$ for $\mathrm{pN}+$ patients (Table 3).

\section{Timing of post-prostatectomy therapy}

In general, the timing of post-prostatectomy therapy for $\mathrm{pN}+$ patients has been guided by the ECOG 3886 trial, which initiated ADT within 12 weeks of prostatectomy.

In select patients with $\mathrm{pN}+$ cancer after $\mathrm{RP}$ and undetectable post-operative PSA, observation without immediate adjuvant therapy is a potential option as described in the EAU guidelines (Grade B) and NCCN guidelines (no category recommendation) (Table 3). In these patients, whether initial observation followed by treatment at the time of biochemical recurrence ("early salvage") may be equally effective compared to immediate 
Table 4 Studies evaluating RP and adjuvant therapies for pathologically node-positive prostate cancer

\begin{tabular}{|c|c|c|c|c|c|}
\hline Study & Study design & $\mathrm{N}$ & Treatment & $\begin{array}{l}\text { Median } \\
\text { follow-up (yr) }\end{array}$ & Study outcomes \\
\hline \multicolumn{6}{|c|}{$\mathrm{RP} \pm$ adjuvant $\mathrm{ADT}$} \\
\hline \multirow{2}{*}{$\begin{array}{l}\text { ECOG } \\
3886(41)\end{array}$} & \multirow{2}{*}{ Randomized trial } & \multirow{2}{*}{98} & \multirow{2}{*}{$\begin{array}{l}\mathrm{RP} \pm \text { immediate } \\
\mathrm{ADT}\end{array}$} & \multirow{2}{*}{11.9} & Median OS 11.3 vs. 13.9 yr; $P=0.04$ \\
\hline & & & & & Median CSS 12.3 yr vs. not reached; $P=0.0004$ \\
\hline \multicolumn{6}{|c|}{$\mathrm{RP} \pm$ adjuvant $\mathrm{RT}$} \\
\hline \multirow{2}{*}{$\begin{array}{l}\text { Da Pozzo } \\
\text { et al. }(45)\end{array}$} & \multirow{2}{*}{$\begin{array}{l}\text { Retrospective, } \\
\text { single institution }\end{array}$} & \multirow[t]{2}{*}{250} & \multirow{2}{*}{$\begin{array}{l}\mathrm{RP}+\text { adjuvant } \\
\mathrm{ADT} \pm \mathrm{RT}\end{array}$} & \multirow[t]{2}{*}{7.6} & Favors adjuvant RT \\
\hline & & & & & HR 0.49 for BCRFS; $P=0.002$ \\
\hline $\begin{array}{l}\text { Briganti } \\
\text { et al. (46) }\end{array}$ & $\begin{array}{l}\text { Retrospective, } \\
\text { two institutions }\end{array}$ & 364 & $\begin{array}{l}\mathrm{RP}+\text { adjuvant } \\
\mathrm{ADT} \pm \mathrm{RT}\end{array}$ & 8.4 & $10-y r$ CSS $70 \%$ vs. $86 \%, P=0.004$ \\
\hline \multirow{3}{*}{$\begin{array}{l}\text { Abdollah } \\
\text { et al. (47) }\end{array}$} & \multirow{3}{*}{$\begin{array}{l}\text { Retrospective, } \\
\text { two institutions }\end{array}$} & \multirow[t]{3}{*}{1,107} & \multirow{3}{*}{$\begin{array}{l}\mathrm{RP}+\text { adjuvant } \\
\mathrm{ADT} \pm \mathrm{RT}\end{array}$} & \multirow[t]{3}{*}{7.1} & Favors adjuvant RT for specific risk groups ${ }^{\dagger}$ \\
\hline & & & & & $8-y r$ OS $75 \%$ vs. $88 \% ; \mathrm{P}<0.001$ \\
\hline & & & & & 8 -yr CSS $86 \%$ vs. $92 \% ; P=0.08$ \\
\hline \multirow{3}{*}{$\begin{array}{l}\text { Touijer } \\
\text { et al. (43) }\end{array}$} & \multirow{3}{*}{$\begin{array}{l}\text { Retrospective, } \\
\text { three institutions }\end{array}$} & \multirow[t]{3}{*}{1,338} & \multirow{3}{*}{$\begin{array}{l}\mathrm{RP} \pm \text { adjuvant } \\
\mathrm{ADT} \pm \mathrm{RT}\end{array}$} & \multirow[t]{3}{*}{5.8} & Favors adjuvant ADT + RT over adjuvant ADT \\
\hline & & & & & HR 0.46 for OS; $\mathrm{P}<0.0001$ \\
\hline & & & & & HR 0.41 for CSS; $P<0.0001$ \\
\hline $\begin{array}{l}\text { Kaplan } \\
\text { et al. (48) }\end{array}$ & $\begin{array}{l}\text { Retrospective, } \\
\text { SEER }\end{array}$ & 577 & & & CSM 1.3 vs. 2.9 deaths/100 person-yr; $P=0.09$ \\
\hline Wong & Retrospective, & 7,225 & $\mathrm{RP} \pm$ adjuvant & 3.8 & Favors adjuvant RT \\
\hline et al. (49) & NCDB & & $A L$ & & $\begin{array}{l}\text { 5-yr OS 85\% (RP alone), 83\% (adjuvant ADT), 88\% } \\
\text { (adjuvant RT), 89\% (adjuvant ADT + RT); P<0.001 }\end{array}$ \\
\hline Jegadeesh & Retrospective, & 1,652 & $\mathrm{RP}+$ adjuvant & 4.4 & Favors adjuvant RT \\
\hline et al. (50) & NCDB & & ADT & & $5-y r$ OS $81 \%$ vs. $88 \% ; \mathrm{P}=0.004$ \\
\hline Gupta & Retrospective, & 8,074 & $\mathrm{RP} \pm$ adjuvant & 4.0 & Favors adjuvant ADT + RT over adjuvant ADT \\
\hline I. (b1) & NCDB & & $A L$ & & HR 0.76 for OS; $P=0.007$ \\
\hline & & & & & Favors adjuvant $A D T+R T$ over RP alone \\
\hline & & & & & HR 0.77 for OS; $P=0.008$ \\
\hline
\end{tabular}

\footnotetext{
${ }^{\dagger}$, Risk groups benefitting from adjuvant RT: (I) 3-4 positive lymph nodes; (II) 1-2 positive lymph nodes + Gleason score $\geq 7+$ stage pT3b/ T4 or positive surgical margins. ${ }^{\ddagger}$, Pairwise analyses showed that combined adjuvant $A D T+R T$ was superior to $R P$ alone $(P=0.007)$ and adjuvant $A D T(P<0.001)$, but not superior to adjuvant $R T(P=0.44)$. RP, radical prostatectomy; $A D T$, androgen deprivation therapy; $R T$, radiotherapy; BCRFS, biochemical relapse-free survival; CSM, cancer-specific mortality; CSS, cancer-specific survival; HR, hazard ratio; NCDB, National Cancer Database; NR, not reported; OM, overall mortality; OS, overall survival; PFS, progression-free survival; SEER, Surveillance Epidemiology \& End Results.
} 
adjuvant therapy is unknown. In one large retrospective study in $\mathrm{pN}+$ patients, the use of adjuvant ADT + RT was associated with an improvement in OS (HR: 0.41; $\mathrm{P}<0.001)$ compared observation and salvage therapy at recurrence (43). The recently reported results from the RAVES (53) and RADICALS (54) randomized trialswhich found equivalent control between adjuvant RT and early salvage RT in mainly early-stage prostate cancer patients after $\mathrm{RP}$ - should not be extrapolated to $\mathrm{pN}+$ patients who constitute a much higher risk population than those studied in the trials.

\section{Conclusions}

There is currently limited randomized evidence to define the optimal treatment strategy for men with node-positive prostate cancer. The studies reviewed in this article provide a rationale for a multimodality treatment approach. For patients with $\mathrm{cN} 1 \mathrm{M} 0$ prostate cancer, one standard option is definitive RT with long-term ADT, and another option is RP. For patients with $\mathrm{pN}+$ disease after RP, adjuvant ADT is supported by the ECOG 3886 trial. Adjuvant $\mathrm{ADT}+\mathrm{RT}$ is another option supported by retrospective studies suggesting that it may improve survival compared to adjuvant $\mathrm{ADT}$ alone. For select $\mathrm{pN}+$ patients, observation could also be considered. Current international guideline recommendations for both $\mathrm{cN} 1 \mathrm{M} 0$ and $\mathrm{pN}+$ diagnoses are summarized in Table 3.

The outcomes summarized here are reflective of a heterogenous population contained in mostly retrospective studies which have methodological limitations. More clinical trials are needed for this understudied patient population to provide high-quality evidence to guide treatment decision-making. One such trial is NRG GU008 (NCT 04134260), which for patients with $\mathrm{pN}+$ disease after $\mathrm{RP}$ is comparing salvage $\mathrm{RT}+\mathrm{ADT} v s$. $\mathrm{RT}+\mathrm{ADT}$ + abiraterone and apalutamide. Intensifying treatment for this group of patients with stage IV disease is likely needed to maximize long-term survival and the potential for cure. Of note, the incidence of node-positive prostate cancer at diagnosis is currently increasing, coincident with decreased PSA screening and enhanced ability to detect occult nodal metastases with new imaging modalities such as the FACBC, choline and prostate-specific membrane antigen PET scans (55). This increase may provide an opportunity for improved participation in prospective randomized trials designed to test the optimal management of node-positive prostate cancer.

\section{Acknowledgments}

Funding: None.

\section{Footnote}

Provenance and Peer Review: This article was commissioned by the Guest Editors (Badrinath R. Konety, Daniel W. Lin) for the series "Current and Future Topics on Prostate Cancer" published in Translational Andrology and Urology. The article has undergone external peer review.

Reporting Checklist: The authors have completed the Narrative Review reporting checklist. Available at http:// dx.doi.org/10.21037/tau-20-1031

Peer Review File: Available at http://dx.doi.org/10.21037/ tau-20-1031

Conflicts of Interest: All authors have completed the ICMJE uniform disclosure form (available at http://dx.doi. org/10.21037/tau-20-1031). The series "Management of Advanced Genitourinary Malignancies" was commissioned by the editorial office without any funding or sponsorship. Dr. RCC reports personal fees from Myovant, personal fees from Abbvie, personal fees from Accuray, personal fees from Blue Earth, outside the submitted work. The authors have no other conflicts of interest to declare.

Etbical Statement: The authors are accountable for all aspects of the work in ensuring that questions related to the accuracy or integrity of any part of the work are appropriately investigated and resolved.

Open Access Statement: This is an Open Access article distributed in accordance with the Creative Commons Attribution-NonCommercial-NoDerivs 4.0 International License (CC BY-NC-ND 4.0), which permits the noncommercial replication and distribution of the article with the strict proviso that no changes or edits are made and the original work is properly cited (including links to both the formal publication through the relevant DOI and the license). See: https://creativecommons.org/licenses/by-nc-nd/4.0/.

\section{References}

1. Siegel RL, Miller KD, Jemal A. Cancer statistics, 2020. CA Cancer J Clin 2020;70:7-30. 
2. Amin MB, Edge SB. AJCC cancer staging manual. 8th ed. New York: Springer, 2017.

3. Schröder FH, Kurth KH, Fossa SD, et al. Early versus delayed endocrine treatment of T2-T3 pN1-3 M0 prostate cancer without local treatment of the primary tumour: final results of European Organisation for the Research and Treatment of Cancer protocol 30846 after 13 years of follow-up (a randomised controlled trial). Eur Urol 2009;55:14-22.

4. James ND, de Bono JS, Spears MR, et al. Abiraterone for prostate cancer not previously treated with hormone therapy. N Engl J Med 2017;377:338-51.

5. Fizazi K, Faivre L, Lesaunier F, et al. Androgen deprivation therapy plus docetaxel and estramustine versus androgen deprivation therapy alone for high-risk localised prostate cancer (GETUG 12): a phase 3 randomised controlled trial. Lancet Oncol 2015;16:787-94.

6. James ND, Sydes MR, Clarke NW, et al. Addition of docetaxel, zoledronic acid, or both to first-line longterm hormone therapy in prostate cancer (STAMPEDE): survival results from an adaptive, multiarm, multistage, platform randomised controlled trial. Lancet 2016;387:1163-77.

7. Hussain M, Tangen CM, Berry DL, et al. Intermittent versus continuous androgen deprivation in prostate cancer. N Engl J Med 2013;368:1314-25.

8. Fizazi K, Tran N, Fein L, et al. Abiraterone acetate plus prednisone in patients with newly diagnosed highrisk metastatic castration-sensitive prostate cancer (LATITUDE): final overall survival analysis of a randomised, double-blind, phase 3 trial. Lancet Oncol 2019;20:686-700.

9. Davis ID, Martin AJ, Stockler MR, et al. Enzalutamide with standard first-line therapy in metastatic prostate cancer. N Engl J Med 2019;381:121-31.

10. Chi KN, Agarwal N, Bjartell A, et al. Apalutamide for metastatic, castration-sensitive prostate cancer. N Engl J Med 2019;381:13-24.

11. Widmark A, Klepp O, Solberg A, et al. Endocrine treatment, with or without radiotherapy, in locally advanced prostate cancer (SPCG-7/SFUO-3): an open randomised phase III trial. Lancet 2009;373:301-8.

12. Mason MD, Parulekar WR, Sydes MR, et al. Final report of the intergroup randomized study of combined androgen-deprivation therapy plus radiotherapy versus androgen-deprivation therapy alone in locally advanced prostate cancer. J Clin Oncol 2015;33:2143-50.

13. Parker CC, James ND, Brawley CD, et al. Radiotherapy to the primary tumour for newly diagnosed, metastatic prostate cancer (STAMPEDE): a randomised controlled phase 3 trial. Lancet 2018;392:2353-66.

14. Zagars GK, Pollack A, von Eschenbach AC. Addition of radiation therapy to androgen ablation improves outcome for subclinically node-positive prostate cancer. Urology 2001;58:233-9.

15. Tward JD, Kokeny KE, Shrieve DC. Radiation therapy for clinically node-positive prostate adenocarcinoma is correlated with improved overall and prostate cancerspecific survival. Pract Radiat Oncol 2013;3:234-40.

16. Rusthoven CG, Carlson JA, Waxweiler TV, et al. The impact of definitive local therapy for lymph node-positive prostate cancer: a population-based study. Int J Radiat Oncol Biol Phys 2014;88:1064-73.

17. Lin CC, Gray PJ, Jemal A, et al. Androgen deprivation with or without radiation therapy for clinically node-positive prostate cancer. J Natl Cancer Inst 2015;107:djv119.

18. James ND, Spears MR, Clarke NW, et al. Failure-free survival and radiotherapy in patients with newly diagnosed nonmetastatic prostate cancer: data from patients in the control arm of the STAMPEDE trial. JAMA Oncol 2016;2:348-57.

19. Lawton CA, Winter K, Grignon D, et al. Androgen suppression plus radiation versus radiation alone for patients with stage D1/pathologic node-positive adenocarcinoma of the prostate: updated results based on national prospective randomized trial Radiation Therapy Oncology Group 85-31. J Clin Oncol 2005;23:800-7.

20. Granfors T, Modig H, Damber JE, et al. Long-term followup of a randomized study of locally advanced prostate cancer treated with combined orchiectomy and external radiotherapy versus radiotherapy alone. J Urol 2006;176:544-7.

21. Mottet N, Bellmunt J, Bolla M, et al. EAU-ESTROSIOG Guidelines on Prostate Cancer. Part 1: Screening, diagnosis, and local treatment with curative intent. Eur Urol 2017;71:618-29.

22. Lieng H, Kneebone A, Hayden AJ, et al. Radiotherapy for node-positive prostate cancer: 2019 Recommendations of the Australian and New Zealand Radiation Oncology Genito-Urinary group. Radiother Oncol 2019;140:68-75.

23. National Comprehensive Cancer Network. Prostate Cancer (Version 2.2020). Accessed 22 September 2020.

24. Engel J, Bastian PJ, Baur H, et al. Survival benefit of radical prostatectomy in lymph node-positive patients with prostate cancer. Eur Urol 2010;57:754-61. 
25. Seisen T, Vetterlein MW, Karabon P, et al. Efficacy of local treatment in prostate cancer patients with clinically pelvic lymph node-positive disease at initial diagnosis. Eur Urol 2018;73:452-61.

26. Denham JW, Steigler A, Lamb DS, et al. Short-term neoadjuvant androgen deprivation and radiotherapy for locally advanced prostate cancer: 10-year data from the TROG 96.01 randomised trial. Lancet Oncol 2011;12:451-9.

27. D'Amico AV, Chen MH, Renshaw AA, et al. Androgen suppression and radiation vs radiation alone for prostate cancer: a randomized trial. JAMA 2008;299:289-95.

28. Jones CU, Hunt D, McGowan DG, et al. Radiotherapy and short-term androgen deprivation for localized prostate cancer. N Engl J Med 2011;365:107-18.

29. Bolla M, de Reijke TM, Van Tienhoven G, et al. Duration of androgen suppression in the treatment of prostate cancer. N Engl J Med 2009;360:2516-27.

30. Lawton CAF, Lin X, Hanks GE, et al. Duration of androgen deprivation in locally advanced prostate cancer: long-term update of NRG oncology RTOG 9202. Int J Radiat Oncol Biol Phys 2017;98:296-303.

31. Kyriakopoulos CE, Chen YH, Carducci MA, et al. Chemohormonal therapy in metastatic hormonesensitive prostate cancer: long-term survival analysis of the randomized phase III E3805 CHAARTED trial. J Clin Oncol 2018;36:1080-7.

32. Bhindi B, Rangel LJ, Mason RJ, et al. Impact of radical prostatectomy on long-term oncologic outcomes in a matched cohort of men with pathological node positive prostate cancer managed by castration. J Urol 2017;198:86-91.

33. Steuber T, Budaus L, Walz J, et al. Radical prostatectomy improves progression-free and cancer-specific survival in men with lymph node positive prostate cancer in the prostate-specific antigen era: a confirmatory study. BJU Int 2011;107:1755-61.

34. Zwergel U, Lehmann J, Wullich B, et al. Lymph node positive prostate cancer: long-term survival data after radical prostatectomy. J Urol 2004;171:1128-31.

35. Cheng L, Zincke H, Blute ML, et al. Risk of prostate carcinoma death in patients with lymph node metastasis. Cancer 2001;91:66-73.

36. Boorjian SA, Thompson RH, Siddiqui S, et al. Longterm outcome after radical prostatectomy for patients with lymph node positive prostate cancer in the prostate specific antigen era. J Urol 2007;178:864-70; discussion 870-1.

37. Touijer KA, Mazzola CR, Sjoberg DD, et al. Long-term outcomes of patients with lymph node metastasis treated with radical prostatectomy without adjuvant androgendeprivation therapy. Eur Urol 2014;65:20-5.

38. Gandaglia G, Soligo M, Battaglia A, et al. Which patients with clinically node-positive prostate cancer should be considered for radical prostatectomy as part of multimodal treatment? The impact of nodal burden on long-term outcomes. Eur Urol 2019;75:817-25.

39. Moschini M, Sharma V, Zattoni F, et al. Natural history of clinical recurrence patterns of lymph node-positive prostate cancer after radical prostatectomy. Eur Urol 2016;69:135-42.

40. Abdollah F, Gandaglia G, Suardi N, et al. More extensive pelvic lymph node dissection improves survival in patients with node-positive prostate cancer. Eur Urol 2015;67:212-9.

41. Messing EM, Manola J, Yao J, et al. Immediate versus deferred androgen deprivation treatment in patients with node-positive prostate cancer after radical prostatectomy and pelvic lymphadenectomy. Lancet Oncol 2006;7:472-9.

42. Wong YN, Freedland S, Egleston B, et al. Role of androgen deprivation therapy for node-positive prostate cancer. J Clin Oncol 2009;27:100-5.

43. Touijer KA, Karnes RJ, Passoni N, et al. Survival outcomes of men with lymph node-positive prostate cancer after radical prostatectomy: a comparative analysis of different postoperative management strategies. Eur Urol 2018;73:890-6.

44. Nini A, Gandaglia G, Fossati N, et al. Patterns of clinical recurrence of node-positive prostate cancer and impact on long-term survival. Eur Urol 2015;68:777-84.

45. Da Pozzo LF, Cozzarini C, Briganti A, et al. Long-term follow-up of patients with prostate cancer and nodal metastases treated by pelvic lymphadenectomy and radical prostatectomy: the positive impact of adjuvant radiotherapy. Eur Urol 2009;55:1003-11.

46. Briganti A, Karnes RJ, Da Pozzo LF, et al. Combination of adjuvant hormonal and radiation therapy significantly prolongs survival of patients with $\mathrm{p} T 2-4 \mathrm{pN}+$ prostate cancer: results of a matched analysis. Eur Urol 2011;59:832-40.

47. Abdollah F, Karnes RJ, Suardi N, et al. Impact of adjuvant radiotherapy on survival of patients with node-positive prostate cancer. J Clin Oncol 2014;32:3939-47.

48. Kaplan JR, Kowalczyk KJ, Borza T, et al. Patterns of care and outcomes of radiotherapy for lymph node positivity after radical prostatectomy. BJU Int 2013;111:1208-14.

49. Wong AT, Schwartz D, Osborn V, et al. Adjuvant radiation 
with hormonal therapy is associated with improved survival in men with pathologically involved lymph nodes after radical surgery for prostate cancer. Urol Oncol 2016;34:529.e15-20.

50. Jegadeesh N, Liu Y, Zhang C, et al. The role of adjuvant radiotherapy in pathologically lymph node-positive prostate cancer. Cancer 2017;123:512-20.

51. Gupta M, Patel HD, Schwen ZR, et al. Adjuvant radiation with androgen-deprivation therapy for men with lymph node metastases after radical prostatectomy: identifying men who benefit. BJU Int 2019;123:252-60.

52. Abdollah F, Dalela D, Sood A, et al. Impact of adjuvant radiotherapy in node-positive prostate cancer patients: the

Cite this article as: D'Rummo KA, Chen RC, Shen X. Narrative review of management strategies and outcomes in node-positive prostate cancer. Transl Androl Urol 2021;10(7):31763187. doi: $10.21037 /$ tau-20-1031 importance of patient selection. Eur Urol 2018;74:253-6.

53. Kneebone A, Fraser-Browne C, Duchesne GM, et al. Adjuvant radiotherapy versus early salvage radiotherapy following radical prostatectomy (TROG 08.03/ANZUP RAVES): a randomised, controlled, phase 3, noninferiority trial. Lancet Oncol 2020;21:1331-40.

54. Parker CC, Clarke NW, Cook AD, et al. Timing of radiotherapy after radical prostatectomy (RADICALSRT): a randomised, controlled phase 3 trial. Lancet 2020;396:1413-21.

55. Bernstein AN, Shoag JE, Golan R, et al. Contemporary incidence and outcomes of prostate cancer lymph node metastases. J Urol 2018;199:1510-7. 